\title{
Educação Física escolar em tempos de Covid- I9: o ensino do esporte e a paralisação dos megaeventos
}

\author{
School Physical Education in covid- 9 times: \\ sport teaching and megaevent stopping
}

Educación Física escolar en veces Covid-19:
enseñanza de deporte y parada mega event Leonardo Carlos de Andrade'

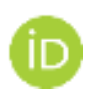

https://orcid.org/0000-0002-0324-6079

Regina Queiroz Silva ${ }^{2}$

iD

https://orcid.org/0000-0002-5668-1664

Eugênio Lopes dos Santos Junior ${ }^{3}$

https://orcid.org/0000-0002-5030-1245

\begin{abstract}
Resumo: Diante do cenário expansivo do coronavírus (Covid-19) as escolas goianienses suspenderam as atividades presenciais e, por conseguinte, assumiram aulas remotas como égide. Este artigo tem como objetivo expor os elementos teórico-metodológicos de uma experiência desenvolvida pela disciplina Educação Física à luz de um referencial histórico-crítico, no interior da Educação Básica, em meio ao distanciamento social. Tomamos como centralidade do processo didático a paralisação dos eventos esportivos e o dilema ético implícito nessa ação. As categorias determinantes para essa mediação foram conteúdo, forma e destinatário, além de um conhecimento próprio do campo, que é o esporte. Entendemos que apesar do êxito da proposta didática, encontramos obstáculos demasiados, portanto legitimamos o caráter provisório (e improvisado) das aulas remotas e enfatizamos a importância da escola regular e presencial.
\end{abstract}

Palavras-chave: Educação física. Educação básica. Esporte. Coronavírus.

\footnotetext{
' Especialista em Educação Física Escolar e Mestrando em Educação Física. Professor do Instituto Federal Goiano. leonardoandradeprof@gmail.com

${ }^{2}$ Especialista em Educação Física Escolar. Professora da Educação Básica. E.I.G. rqueirozs@gmail.com

${ }^{3}$ Especialista em Educação Física Escolar e Mestrando em Educação Física. Professor. ASSOBES ENSINO SUPERIOR. eeugeniolsj@gmail.com
} 
Abstract: Faced with the expansive scenario of the coronavirus (Covid-19), the schools in Goiás suspended the face-to-face activities and, therefore, took remote classes as aegis. This article aims to expose the theoretical and methodological elements of an experience developed by the Physical Education discipline in the light of a historical-critical framework, within Basic Education, amid social distance. We take as a central part of the didactic process the paralysis of sporting events and the ethical dilemma implicit in this action. The determining categories for this mediation were content, form and recipient, in addition to a knowledge of the field, which is sport. We understand that despite the success of the didactic proposal, we encounter too many obstacles, so we legitimize the provisional (and improvised) nature of remote classes and emphasize the importance of regular and face-toface schools.

Keywords: Physical education. Basic education. Sport. Coronavirus.

Resumen: Ante el escenario expansivo del Virus Corona (CoVID-19), las escuelas en Goiás suspendieron sus actividades presenciales $y$, por lo tanto, tomaron clases remotas como égida. Este artículo pretende exponer los elementos teóricos y metodológicos de una experiencia desarrollada por la disciplina de Educación Física a la luz de un marco histórico-crítico, dentro de la Educación Básica, en medio de la distancia social. Tomamos como parte central del proceso didáctico la parálisis de los eventos deportivos y el dilema ético implícito en esta acción. Las categorías determinantes para esta mediación fueron contenido, forma y destinatario, además del objeto de campo que es Cultura Corporal. Entendemos que, a pesar del éxito de la propuesta didáctica, encontramos demasiados obstáculos, por lo que legitimamos la naturaleza provisional (e improvisada) de las clases remotas y enfatizamos la importancia de las escuelas regulares y presenciales.

Palabras clave: Educación física. Educación básica. Deporte. Coronavirus.

\section{Introdução}

O ano de 2020 surge na história moderna como marco, pois devido a expansão pandêmica do novo coronavírus, causador da Covid-19, famílias, indústrias, escolas e eventos tiveram de se adaptar a uma nova ordem, a ordem de recessão. Dentre os impactados, estão os megaeventos esportivos, que também foram suspensos. Esse fato gerou uma discussão com alunos do Ensino Médio, no âmbito da Educação Física escolar, sobre as possíveis contradições oriundas do esporte contemporâneo.

Desse modo, este trabalho tem como objetivo expor uma experiência desenvolvida pela Educação Física no interior da educação básica em uma escola goianiense, em meio a ordem de recessão relacionada à problematização da suspensão dos megaeventos esportivos. Em relação à metodologia, amparados em Severino (2002), ressaltamos que esse artigo se configura como um relato de experiência, que se propõe a expor as circunstâncias e o desenvolvimento teórico-metodológico do trabalho pedagógico em questão.

Como propósito secundário, vamos expor algumas contradições oriundas do ensino remoto, pois apesar do êxito da proposta didática, entendemos que o ensino virtual não substitui a educação presencial, portanto legitimamos o caráter provisório (e improvisado) das aulas remotas e enfatizamos a importância da escola regular e presencial.

Compreendemos que este relato poderá contribuir para um diagnóstico das circunstâncias e adversidades que a educação básica, e mais precisamente a educação física escolar, enfrenta durante o período de recessão provocada pela pandemia da Covid-1 9 (Coronavírus). 
Leonardo Carlos de Andrade, Regina Queiroz Silva e Eugênio Lopes dos Santos Junior

Saviani (20/3), ressalta que o valor da educação escolar se dá como lócus privilegiado da apropriação do conhecimento clássico, mais desenvolvido e intencional. Em suma, a escola é o espaço de apreensão do saber sistematizado e elaborado pela ciência predominantemente, por isso, ao convertermos esse conhecimento em conhecimento escolar, fazemos articulações com os fatos sociais advindos da prática social e para a prática social, que é comum aos professores e alunos.

Desta prática, emanam as contradições da relação do indivíduo e sociedade, que para Lukács (2010), são engendradas sobretudo por políticas econômicas, pela acumulação flexível e pelas crises cíclicas. Esta última, por sua vez, tem múltiplas facetas, pois pode advir do caráter econômico, científico, religioso, político, ou até mesmo patológico, como já visto no episódio da cruel Gripe Espanhola. Por isso, frente a essa crise do Coronavírus, o esporte, como as demais manifestações sociais, sofreu forte impacto, de modo ainda mais expressivo no âmbito do rendimento. Essa manifestação emergente da prática social fomentou a questão norteadora desse relato, "Como a Educação Física poderia problematizar esse tema na escola?".

Pautando-se nos dados concretos da realidade, vimos saltear aos nossos olhos diversas expressões de megaeventos afetados pela expansão da doença. No automobilismo, o GranPrix de Mônaco foi cancelado em 24 de maio de 2020; no Tênis, a edição $134^{\text {a }}$ do torneio de Wimbledon foi transferida para 202I; a Liga Mundial de Surfe (WSL) cancelou todas competições do primeiro semestre de 2020; e até mesmo os seculares Jogos Olímpicos foram adiados para 202I.

Estes dados foram captados a partir de uma concepção histórico-crítica de Educação Física, que tem como objeto os conhecimentos advindos da Cultura Corporal, que por sua vez representam a dança, a ginástica, a capoeira, as lutas, o esporte e outros componentes (ANDRADE et al., 2020). A Cultura Corporal também irá se reproduzir, reter, velar e revelar em um movimento dialético com o real as suas expressões educativas. Por isso, já alertamos que essa experiência foge dos moldes pragmáticos da Educação Física, dialogando e se embasando na pedagogia histórico-crítica e na abordagem crítico- superadora (SOARES et al., I992; SAVIANI, 2013). Isso possibilitou pensarmos "o que ensinar" (esportes), "como ensinar" (aulas remotas) e "para quem" ensinar (Ensino Médio) (ANDRADE, 2020).

As aulas remotas foram uma determinidade 4 da situação de reclusão social, onde os professores da rede particular de educação tiveram de continuar a ministrar aulas nos mesmos horários e dias pelas plataformas virtuais. Por isso, em nosso planejamento de "formas", tivemos de adequar o ensino a essa nuance. Em nossa análise, entender o conceito de Trabalho Educativo ${ }^{5}$ e se apropriar dele é

\footnotetext{
4 Ver Lukács (2010).

${ }^{5}$ Produzir em cada indivíduo a humanidade coletiva, pelos conhecimentos mais desenvolvidos e pelas formas mais adequadas (SAVIANI, 20I3).
}

Olhar de professor, Ponta Grossa, v. 24, p. I-8, e-15428.024, 2021.

Disponível em <https://revistas2.uepg.br/index.php/olhardeprofessor> 
Educação Física escolar em tempos de Covid-19: o ensino do esporte e a paralisação dos megaeventos fundamental para enfrentar as contradições e demandas de um ensino remoto repentino, que surpreendeu os professores e causou verdadeira metamorfose pedagógica.

Vendo a totalidade de determinações que o fenômeno esportivo compõe e o papel do professor, visamos aqui desvelar aquilo que é velado nos meandros da organização escolar. Por isso, nos propomos neste relato, expor uma experiência de ensino do esporte por aulas remotas, articulando este conteúdo com as limitações sociais impostas pelo coronavírus, sobretudo nos eventos esportivos.

\section{Experiências remotas: Educação Física em foco}

Diante do cenário expansivo do Coronavírus (Covid-19) as escolas goianienses suspenderam atividades presenciais, mas de acordo com as indicações da Secretaria de Educação do Estado de Goiás, professores teriam de continuar ministrando aulas remotamente, e isso foi rapidamente adotado pela rede de educação particular.

Neste texto vamos nos ater ao relato e não entraremos em questões como precarização do trabalho docente e colonização da vida do professor (BALL, 2002). Por ora, basta evidenciar que esses determinantes existem e foram maximizados nesse tempo.

Essa experiência foi desenvolvida em uma escola de educação básica, em Goiânia (Goiás), que faz parte de uma rede nacional, que conta com alunos da Educação Infantil ao Ensino Médio. Apesar dos professores cumprirem sua carga horária normalmente em várias das séries citadas, exporemos aqui a experiência com $\circ \mathrm{I}^{\circ}$ ano do Ensino Médio, que em nosso olhar traz mais solidez ao relato. $\mathrm{A}$ turma conta com 40 alunos com idade média de 15 e 16 anos, a maioria possui computadores, celulares e boa conexão de internet em casa.

Buscamos nos desdobramentos sociais um eixo norteador para uma reflexão pedagógica. Como supracitado, muitas das grandes competições esportivas, a nível mundial, paralisaram devido à crise do Covid-19. Um novo exemplo é a suspensão da temporada da NBA, após a testagem positiva de um atleta. $O$ fato expôs ao mundo que o coronavírus pode trazer sequelas de grande proporção (ou óbito) para quem é contaminado, como complicações cardiorrespiratórias. Porém, algumas competições brasileiras insistiam em persistir, como o Campeonato Acreano de Futebol, que perdurou até meados de abril.

Como ponto de partida, desenvolvemos discussões por videoaulas, estudos dirigidos em textos selecionados e atividades de pesquisa sobre o conceito de espetacularização do esporte, que em outras palavras, se trata da supressão de tudo que representa o esporte (regras, lógica interna, atletas, história, representação lúdica, estética e agonística) e a maximização da lógica do mercado,

Olhar de professor, Ponta Grossa, v. 24, p. I-8, e-15428.024, 2021.

Disponível em <https://revistas2.uepg.br/index.php/olhardeprofessor> 
nas quais os esportes são conduzidos ao processo de mercantilização (MARCHI JÚNIOR, 200I). Sempre ao término desses debates, colocávamos em xeque uma situação de contradição presente em exemplos de paralisação de megaeventos, como: "Porque o patrocinador da Copa América não quer que o evento seja adiado para 202I ? Essa não seria uma medida adequada para as melhores condições do esporte?".

Essas provocações fomentaram reflexões dos alunos acerca dos conhecimentos que estavam sendo suprimidos por essa espetacularização: $O$ que é esporte? Qual a diferença do esporte rendimento e o esporte da escola? O esporte lazer, entretenimento e o educacional? Nesse enredo, vimos a necessidade de ampliar a visão e criticidade de nossos alunos. A Educação Física explorou novamente por videoaulas (duração de 50 min semanais) a diferença do esporte de participação (lazer), educacional (pedagógico/formação) e de rendimento (profissional). Neste último, destacamos com maior veemência, como a pandemia impacta a indústria do entretenimento e a mídia.

Reunimos alguns textos de autores, cronistas esportivos, reportagens e fizemos um vídeo explicativo com esses conceitos, para que os alunos diante das novas acepções, compreendessem que o esporte, que tem uma essência prática, é carregado de conceitos (indissociáveis), que só percebemos quando refletimos conscientemente ${ }^{6}$. Outra questão levantada foi sobre o esporte-entretenimento e como ele seria afetado diante da pandemia.

Foi observado que os alunos trazem consigo diversos pré-conceitos para a escola e somente após o desenvolvimento do conteúdo esporte, eles reconheceram os conceitos científicos ${ }^{7}$ presentes no objeto, e consequentemente a importância de compreender os múltiplos determinantes (ANDRADE, 2020). Este foi o salto qualitativo ensejado inicialmente, pois após as mediações conceituais acerca do esporte, eles conseguiram compreender que a paralisação da NBA (Basquete) ou da NFL (Futebol Americano), não diz respeito apenas a paralisação de um "jogo", mas sim a manutenção da qualidade do esporte e o cuidado com a vida dos jogadores e famílias, que apesar de terem histórico de atleta, continuam sendo susceptíveis ao Covid-19.

Porém, também foi percebido um certo desleixo de uma minoria de alunos que dificultou a qualidade da reflexão e alcance a toda turma. Estes apresentaram respostas curtas e vazias, como "esporte-entretenimento é bom para divertir", "esporte é saúde", entre outras, que representavam muito mais um descaso do que limitações teóricas. A partir desta situação, ressaltamos que o conhecimento sistematizado não paira no ar, daí a importância do estudo da Educação Física na escola. Nesses casos, insistimos em ações reflexivas por meio de questionamentos (individuais inclusive) e

\footnotetext{
${ }^{6}$ Ver Lukács (2010).

7 Ver Saviani (2013).
}

Olhar de professor, Ponta Grossa, v. 24, p. I-8, e-15428.024, 202 I.

Disponível em <https://revistas2.uepg.br/index.php/olhardeprofessor> 
Educação Física escolar em tempos de Covid-19: o ensino do esporte e a paralisação dos megaeventos sucessivas inserções conceituais superando suas respostas iniciais, que nitidamente exigiam uma maior profundidade.

Dentro das discussões durante esse período de aulas remotas tem sido muito abordado com os alunos o formato da aula de Educação Física, visto que no ambiente escolar presencial, nossa vivência se dá de forma coletiva e com o isolamento social isso não é possível, pois exige um distanciamento interpessoal. Por isso, a maior ênfase foi dada nas discussões conceituais acerca dos conteúdos de jogos coletivos, como jogos de invasão, alvos, entre outros ${ }^{8}$. A via de escape para as propostas de predominância motriz foram as sugestões adaptadas ao ambiente familiar.

Não perdemos de vista a especificidade das atividades corporais, mas adequamos as condições objetivas desse momento. Nas aulas presenciais, os professores parecem assumir uma figura de maior referência, sendo que na experiência remota isso foi secundarizado.

Mesmo com as famílias cobrando das escolas aulas inovadoras, cumprimento do horário presencial, qualidade e dedicação exclusiva dos professores, percebe-se que esse discurso está ligado apenas a algumas disciplinas curriculares, deixando as demais, dentre elas a Educação Física à margem do currículo. Vemos então um real desleixo das famílias frente aos conteúdos dessa disciplina, reproduzindo um estereótipo histórico de marginalização do campo. Todavia, acreditamos que propostas emancipatórias como a deste relato possam contribuir para a superação do estigma carregada pela Educação Física na escola.

Para além dos obstáculos com pequenos grupos e com as famílias, vemos que os alunos com maior acesso às tecnologias e que mantiveram boa frequência (virtual) tiveram um salto qualitativo e uma nova compreensão da paralisação dos eventos esportivos. Podemos dizer, que estes adolescentes tiveram uma tomada de consciência ética (LUKÁCS, 2010).

\section{Considerações finais}

Diante da problemática social, oriunda dos impactos do Coronavírus no esporte de rendimento, os professores de Educação Física viram um potencial de discussão ética, do ponto de vista filosófico. Portanto, os alunos foram colocados diante do dilema, de um lado as competições que são obrigadas a recuar, racionalizando os lucros e por outro preservando a vida dos atletas e do público.

Este relato teve a premissa de responder como a Educação Física poderia problematizar, no ambiente escolar, a suspensão dos megaeventos em tempos pandêmicos. Apontamos que uma possibilidade é a problematização sobre as crenças dos alunos em relação aos elementos envolvidos

\footnotetext{
8 Ver Mitchell, Oslin e Griffin (2003). 
Leonardo Carlos de Andrade, Regina Queiroz Silva e Eugênio Lopes dos Santos Junior nas múltiplas determinações do esporte, objetivando assim o confronto de ideias (sincréticas) e possibilitando mediações em busca de novas sínteses.

Ademais, outros conteúdos do Esporte foram socializados com destreza, garantindo um salto qualitativo dos jovens sobre os conceitos. A pouca adesão dos alunos, as dificuldades de manipulação tecnológica e o desleixo familiar obstaculizaram um melhor resultado do processo. Todavia, vemos que a possibilidade de se pautar nos dados sincrônicos da realidade garante a concretude necessária para o ensino dos conteúdos da Cultura Corporal. Para aqueles professores que passam por esses mesmos embates, evidenciamos que este é um caminho seguro, partindo da materialidade (paralisação dos megaeventos), para a abstração (conceitos do esporte), e retomada da materialidade (prática social consciente).

Por isso, consideramos esta experiência exitosa, pois a Educação Física, mesmo em meio às tribulações da pandemia, pôde contribuir para a formação humana dos alunos e com a socialização de seus conteúdos específicos, apesar dos vários obstáculos supracitados. Todavia, ressaltamos, uma vez mais, que o ensino remoto tem inúmeras limitações e não é a forma de educação escolar mais adequada.

Por fim, diante o cenário de expansão do coronavírus, aparentemente essas aulas remotas tendem a continuar e o professor, assim como o Mito de Sísifo, está fadado a repetir a tarefa de empurrar a pedra até o topo da montanha, por tempo indeterminado.

\section{Referências}

ANDRADE, L. C.; ANDRADE, J. S. D.; LIMA, W. P.; XIMENES, P. Cultura Corporal: o "movimento" dialético entre homem e natureza. Praxia - Revista on-line de Educação Física da UEG, Goiânia, v. 2, p. e2020007, 19 jun. 2020.

BALL, S. J. Reformar escolas/reformar professores e os terrores da performatividade. Revista Portuguesa de Educação, Braga, v. 15, n.02, p. 03-23, 2002.

LUKÁCS, G. Prolegômenos para uma ontologia do ser social: questões de princípios para uma ontologia hoje tornada possível. São Paulo: Boitempo, 2010.

MITCHELL, S.; OSLIN, J.; GRIFFIN, L. Sport fundations for elementary Physical Education: a tactical games approach. Kent. Ohio: Human Kinetics, 2003.

MARCHI JUNIOR, W. "Sacando" o voleibol: do amadorismo à espetacularização da modalidade no Brasil (1970-2000). Tese de Doutorado. Faculdade de Educação Física da Universidade Estadual de Campinas, Campinas, 200I.

SAVIANI, D. Pedagogia histórico-crítica: primeiras aproximações. Campinas: Autores Associados, 2013.

Olhar de professor, Ponta Grossa, v. 24, p. I-8, e-I5428.024, 202I.

Disponível em <https://revistas2.uepg.br/index.php/olhardeprofessor> 
SEVERINO, A. J. Metodologia do Trabalho Científico. São Paulo: Cortez, 2002.

SOARES, C.; TAFFAREL, C. N. Z.; VARJAL, M. E. M. P.; FILHO, L. C.; ESCOBAR, M. O.; BRACHT. W. Metodologia do Ensino de Educação Física. São Paulo: Cortez, 1992.

Recebido em: 16 de maio de 2020.

Versão corrigida recebida em: 13 de agosto de 2020.

Aceito em: 22 de outubro de 2020.

Publicado online em: 01 de abril de 2021 .

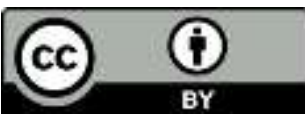

